\title{
Risk Factors for Severe Coronavirus Disease (COVID-19)
}

Authors:

Disclosure:

*Abdulzahra Hussain, ${ }^{1,2}$ Deepak Rao, ${ }^{3}$ Thomas Buttle, ${ }^{3}$ Lynette

Linkson, ${ }^{3}$ William Owen, ${ }^{4}$ Elizabeth Hadley, ${ }^{3}$ Shamsi EL-Hasani ${ }^{5}$

1. General Surgery Department, Doncaster and Bassetlaw Teaching Hospitals, Doncaster, UK

2. College of Medicine, Sheffield University, Sheffield, UK

3. Respiratory Medicine Department, King's College Hospitals NHS Foundation Trust, London, UK

4. Intensive Care Therapy Department, King's College Hospitals NHS Foundation Trust, London, UK

5. General Surgery Department, Kings College Hospitals NHS Foundation Trust, London, UK

*Correspondence to azahrahussain@yahoo.com

Acknowledgements: The authors would like to thank the high dependency unit, respiratory unit, and intensive therapy unit staff for the preparation of the data and management of patients.

Received:

10.06.20

Accepted:

31.07.20

Keywords:

Coronavirus disease (COVID-19), BMI, mortality, obesity.

Citation:

EMJ Respir. 2020;8[1]:120-126.

\section{Abstract}

Background: During the recent coronavirus disease (COVID-19) pandemic there have been several studies implicating an association between obesity, COVID-19 severity, and mortality. This retrospective study aims to investigate the association between obesity, other risk factors, and COVID-19 mortality of patients admitted over a 6-week period to the respiratory units at the authors' hospitals.

Methods: This is a retrospective study of 71 patients who were admitted into a respiratory unit over a 6-week period where the data were analysed for correlation between various risk factors, COVID-19 severity, and mortality. The statistical analysis was performed using excel statistics and SPSS (IBM, Armonk, New York, USA) statistical software. The significance was considered at p<0.05. The multivariate analysis, Z-test, Cox regression, Pearson correlation, and Kaplan-Meier analysis were used.

Results: The mean age of the patients was 65.8 years (range: 35.0-93.0 years) standard deviation (13.21) and the male to female ratio was 2.73 (52:19, respectively). The most frequent comorbidities were obesity (42/71; 59\%), hypertension (36/71; 50\%), diabetes (22/71; 31\%), heart disease (13/71; $18 \%)$, respiratory disease (9/71; 13\%), and cancer (8/71; 11\%). The mean body weight was $83.7 \mathrm{~kg}(60.4-$ $147.7 \mathrm{~kg}$ ) and the mean BMI was $32.2\left(22.0-53.0 \mathrm{~kg} / \mathrm{m}^{2}\right)$. Smoking was reported in $8(11 \%)$ of the patients. There were 20 (83\%) mortalities among patients $>70$ years old $(p<0.0001), 20$ ( $83 \%)$ deaths among male patients ( $p<0.0001), 14$ (58\%) deaths among patients with a $B M I>25 \mathrm{~kg} / \mathrm{m}^{2}(p=0.001), 17$ $(70 \%)$ deaths reported for patients with hypertension $(p=0.008), 6(25 \%)$ mortalities for patients with 
cardiovascular disease $(p=0.001), 14(30 \%)$ deaths among patients who were mechanically ventilated $(p=0.00028)$, and 5 (20\%) mortalities among patients with cancer $(p=0.003)$.

Conclusions: Obesity, cancer, mechanical ventilation, male sex, intensive care unit admission, cardiovascular disease, and hypertension are significant risk factors for mortality in patients with COVID-19.

\section{INTRODUCTION}

Obesity is suggested as a risk factor for severe acute respiratory syndrome coronavirus-2 (SARS-CoV-2) infection, ${ }^{1,2}$ though this has not been confirmed in randomised trials. In the outbreaks of the influenza virus $\mathrm{H} 1 \mathrm{~N} 1$ and SARS, obesity was reported in $23 \%$ of patients and was a predictor and risk factor for severe disease and poor outcomes. ${ }^{3-5}$ This affinity is based on several underlying factors, mostly related to a defective immune system, antigen presentations, cellular and humoral responses, cytokines activation, interleukins interactions, immune system regulation, and adipose tissue inflammation. . $^{6}$ According to the Intensive Care Units National Audit and Research Centre (ICNARC), once the infection is established in patients who are obese, it leads to severe outcomes in the majority." The ICNARC data has shown that $>73 \%$ of newly diagnosed cases of coronavirus disease (COVID-19) had a BMI $>25 \mathrm{~kg} / \mathrm{m}^{2}, 74 \%$ of patients needed advanced respiratory support, and nearly $50 \%$ died in an intensive care unit. The health systems in Western countries with high rates of obesity, including the UK, have experienced challenges whilst managing patients with COVID-19. Despite the huge resources and welldeveloped health infrastructures, the progression to organ failure and death in a significant number of patients, unfortunately, has been confirmed.12,13 The primary endpoint of this article was to investigate obesity as a risk factor for mortality in COVID-19 patients. The secondary endpoints were to assess age, sex, diabetes, cancer, hypertension, smoking, and respiratory and cardiovascular diseases as risk factors for COVID-19 mortality.

\section{METHODS}

\section{Study Design}

This was a retrospective study of 71 consecutive patients with COVID-19 who were admitted and treated at a respiratory unit (RU) at the authors' hospitals. The data was initially retrospectively collected but subsequently populated prospectively during the hospital stay and then analysed. All patients showed severe symptoms of COVID-19 and tested positive for SARSCoV-2 on a reverse transcriptase-PCR assay after a nasopharyngeal swab. All 71 patients (age range: 35-93 years) were admitted to the $R U$ with hypoxaemia.

\section{Setting}

In the university hospitals, the RU was managed and supervised by a consultant respiratory physician. Patients were admitted to the intensive therapy unit (ITU) if they failed respiratory management.

\section{Data Collection}

The data were collected by the respiratory and ITU teams over a 6-week period. Initially retrospectively, then prospectively, the data were collected as the patient's clinical condition developed. The data were collected from case notes and clinical electronic systems; they were saved on Microsoft Excel files with a secured, encrypted password that could only be accessed by the research team. The anonymous data were then passed over to another research team to analyse.

\section{Variables}

The variables included age, sex, BMI, smoking, respiratory and cardiovascular disease, hypertension, diabetes, and cancer. The mortality was calculated for each of these risk factors. The data source was the daily patient records from the RU and ITU.

\section{Bias}

This is a retrospective study of a cohort of patients; there was no selection bias as all patients were included over the 6-week study 
period. The clinical decisions were governed by clinical guidelines and supervised by experienced consultant physicians.

\section{Quantitative Variables}

The most important demographic features, comorbidities, and mortality rates were reported. The data were added to the Microsoft Excel file as they emerged, which was frequently both during admission and during progression of the disease.

\section{Statistical Analysis}

Microsoft Excel statistics and XLSTAT (Addinsoft, Paris, France) statistical software was used. The mean was used to compensate for missing data related to smoking and BMI. The rest of the data for all patients were available and there was no loss to follow-up. The significance was considered at $\mathrm{p}<0.05$. Z-test, multivariate analysis, logistic regression, and correlation tests were used. Cox regression analysis was used to assess the survival and calculate the proportional hazard ratios. A Kaplan-Meier survival graph was produced to show the survival pattern (Figure 1).

\section{RESULTS}

All of the patients' data were included at all stages of the study. The mean age of the patients was
65.8 years (range: $35-93$ years) and the male to female ratio was 2.73 (52:19). The most frequent comorbidities were diabetes (22/71; 31\%), heart disease (13/71; 18\%), hypertension (36/71; 50\%), respiratory disease $(9 / 71 ; 12.7 \%)$, and cancer (8/71; 11\%).

The mean body weight was $83.7 \mathrm{~kg}(60.4-147.7 \mathrm{~kg})$ and the mean BMI was 32.2 (standard deviation [SD]: 6.8; range: $22.0-52.0 \mathrm{~kg} / \mathrm{m}^{2}$ ). Seventeen patients (24\%) were managed at Level 2 of care, while 54 were managed at Level 3 of care. The mean number of days needed by the patients to achieve $>40 \%$ fraction of inspired oxygen $\left(\mathrm{FiO}_{2}\right)$ was 1.09 days (SD: 1.23). The mean $\mathrm{O}_{2}$ after 12 hours of starting continuous positive airway pressure (CPAP) was $10.35 \mathrm{~L} / \mathrm{min}$ (SD: 4.38); the partial pressure of oxygen before CPAP $\left(\mathrm{SpO}_{2}\right.$ pre-CPAP) was 93.60\% (SD: 0.04); the $\mathrm{FiO}_{2}$ (last pre-CPAP) was 69.80\% (SD: 0.13); the $\mathrm{SPO}_{2} / \mathrm{FiO}_{2}$ ratio pre-CPAP was 1.40 (SD: 0.37); the mean respiratory rate pre-CPAP was 24.68 breaths per minute (SD: 4.97); the mean days on CPAP was 3.71 (SD: 2.23); and the mean maximum positive end-expiratory pressure (PEEP) was $12.78 \mathrm{cmH}_{2} \mathrm{O}$ (SD: 2.27)

Of the 71 patients, 25 (35\%) were discharged, while 46 (65\%) were intubated and managed at Level 3 of care.

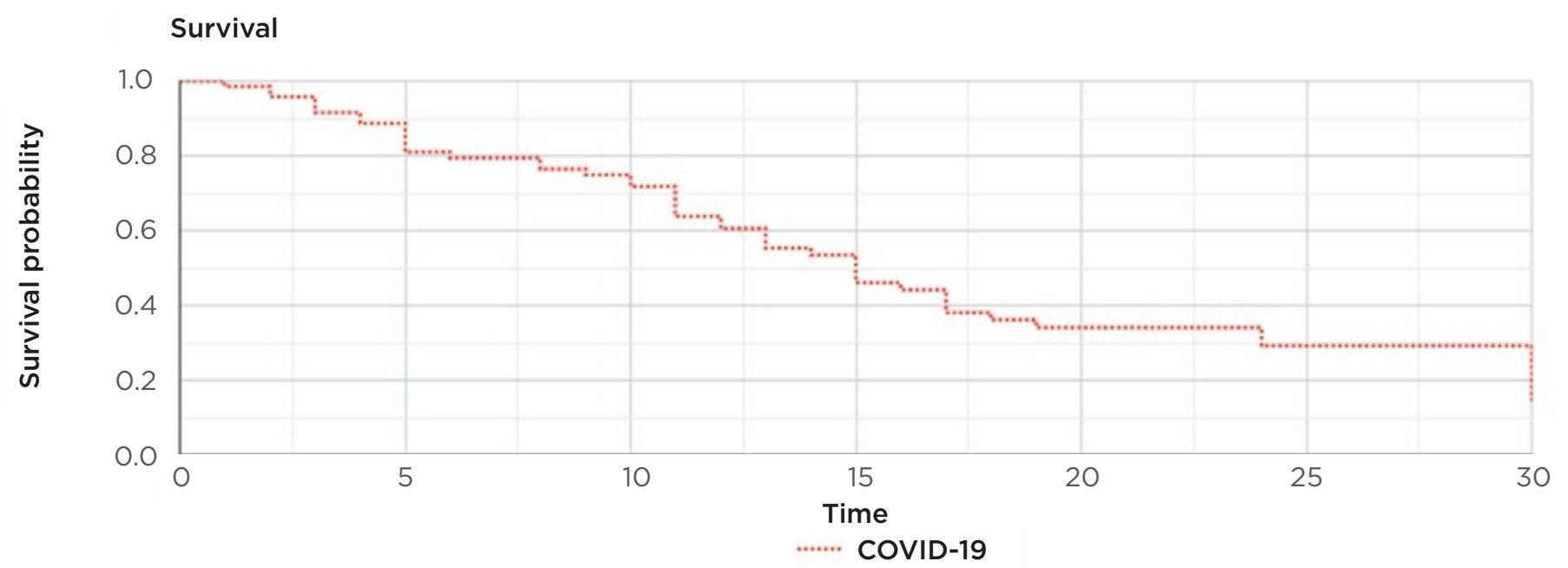

Figure 1: Kaplan-Meier survival graph.

COVID-19: coronavirus disease. 
Twenty-eight patients (39\%) were mechanically ventilated. Ten patients (14\%) died in the RU and the total mortality up to the date of writing this report was 24 (34\%). At present, 16 patients (23\%) are still in hospital. The mean length of stay was 10.3 days (SD: 4.9 ), the mean C-reactive protein level on admission was $147.30 \mathrm{mg} / \mathrm{L}$ (SD: 99.93), the peak C-reactive protein was $264.42 \mathrm{mg} / \mathrm{L}$ (SD: 113.99), and the D-Dimer mean was $9,742 \mathrm{ng} / \mathrm{mL}$ (range: 224-80,000 ng/mL; SD: 22515) (Table 1). The incidence of obesity in this cohort of patients was $59 \%$. The length of hospital stay ranged from 5 to 19 days (SD: 4.9), excluding the 16 patients still in hospital at the time of writing.

Table 1: Characteristic features and mortality.

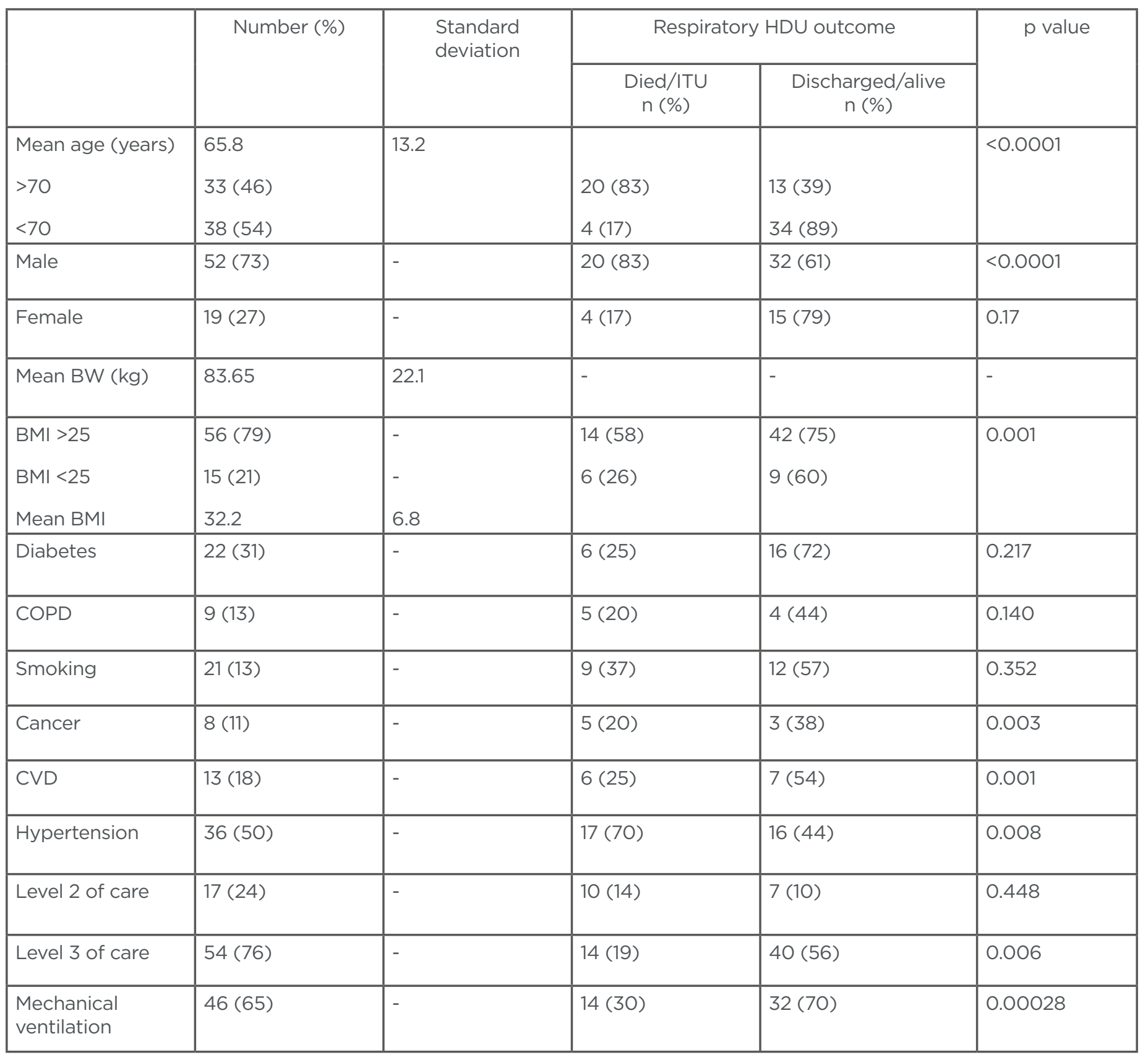

BW: body weight; COPD: chronic obstructive pulmonary disease; CVD: cardiovascular disease; HDU: high dependency unit; ITU: intensive therapy unit. 
Multivariate analysis showed a significant association between all the aforementioned risk factors (except chronic obstructive pulmonary disease [COPD] and diabetes; $p=0.140$ and $\mathrm{p}=0.217$, respectively) and COVID-19 mortality $(p=0.000172)$. There were $20(83 \%)$ mortalities among patients $>70$ years old $(p<0.0001)$ and 20 $(83 \%)$ deaths among male patients $(p<0.0001)$. There were 14 (58\%) deaths among patients with a $\mathrm{BMI}>25 \mathrm{~kg} / \mathrm{m}^{2}(\mathrm{p}=0.001), 17(70 \%)$ deaths among patients with hypertension $(p=0.008)$, 6 (25\%) mortalities among patients with cardiovascular disease ( $p=0.001), 9(37 \%)$ deaths among those who smoked $(p<0.00001)$, and 5 (20\%) mortalities among patients with cancer $(p=0.003)$. On multi-regression analysis, BMI $(p<0.0001)$, cancer $(p=0.003)$, and smoking $(p<0.0001)$ significantly predicted mortality (Table 1). Cox regression analysis showed an increased proportional hazard ratio for age, heart disease, hypertension, cancer, obesity, sex, and the need for mechanical ventilation (Table 2).

\section{DISCUSSION}

The most striking findings of this study are that obesity is pivotal in severe COVID-19 progression and mortality $(p=0.043)$. Obesity is a complex disease with several factors increasing the likelihood of severe disease and mortality in cases of COVID-19, among them being a local prevalence of obesity; the associated comorbidities of obesity such as diabetes, cardiovascular, stroke, respiratory disease, and defective innate and adaptive immune responses; and the exposure of the patients to the virus because of their frequent hospital visits and need for medical support. ${ }^{14-16}$ It is not surprising that a significant number of severe COVID-19 cases led to mortality in highly prevalent areas for obesity such as the USA ${ }^{17}$ and the UK. ${ }^{11}$

A recent meta-analysis showed that obesity, age, critical illness, the need for advanced respiratory support, and severe comorbidities are risk factors for mortality in patients with COVID-19.18 Obesity is thought to be a major risk factor for COVID-19 mortality because of the impaired immune response, cellular failure to control the infection, and the effect of adipose tissue mass, to which the virus affinity is higher than to the lung tissues..$^{19,20}$ The overexpression of inflammatory adipokines from visceral fat depots can affect the immune response, impair the chemotaxis, and alter the macrophage differentiation. ${ }^{21}$ Other publications had confirmed the association between obesity and mortality and leading organisations such as the British Obesity and Metabolic Surgery Society (BOMSS) have called for increasing bariatric surgery capacity to protect patients with obesity and reduce the definitive risks if they go on to develop COVID-19.22

The mean age of the participants was of 65.8 years, and several studies on COVID-19 have confirmed that elderly people are likely to experience the severe form of the infection. ${ }^{23,24}$ Other important features strongly associated with COVID-19 mortality are male sex, heart disease, respiratory disease, and cancer. Previous studies have also shown the vulnerability of hypertensive patients for severe infection. ${ }^{25}$

It is known that the virus attaches itself to cells via the angiotensin-converting enzyme-2 (ACE2) receptors for purposes of entry, replication, and subsequent shedding. ${ }^{26}$ ACE2 are a usual target in the management of hypertension as their receptors are abundant in the lung, heart, kidney, and gastrointestinal tract. Administering ACE2 inhibitors blocks the receptors and reduces angiotensin-1. Angiotensin II receptor blockers are able to reduce inflammation and could diminish the potential for the development of either acute respiratory distress syndrome, myocarditis, or acute kidney injury, which is known to occur in patients with COVID-19. ${ }^{27}$

Several studies have reported hypertension as an indicator of severity without adjusting the confounding factors. The accurate association is not known and larger studies are needed to address this controversy. ${ }^{28,29}$

Smoking is frequently reported in cases of COVID-19, and it is a risk for severity, ITU admission, and mortality; ${ }^{30}$ this is because smoking increases the levels of goblet cells and ACE2 receptors. Theoretically speaking, higher levels of smoking leads to additional ACE2 receptors which gives more opportunity for the SARS-CoV-2 to attach to cells. ${ }^{31}$ If the viral load is high, then the expected outcome is a severe disease and possible mortality.

It is, however, not clear whether ex-smokers will be at as high a risk as current smokers, and more studies are needed to elucidate this. 
Table 2: Cox regression analysis variables.

\begin{tabular}{|l|l|l|l|l|l|l|l|l|}
\hline & & & & & & & \multicolumn{2}{|l|}{$95 \%$ Cl for $\operatorname{Exp}(\mathrm{B})$} \\
\hline & B & SE & Wald & DF & Sig. & Exp(B) & Lower & Upper \\
\hline Age & 0.064 & 0.030 & 4.626 & 1 & 0.031 & 1.066 & 1.006 & 1.130 \\
\hline Smoking & -0.503 & 0.574 & 0.768 & 1 & 0.381 & 0.605 & 0.196 & 1.863 \\
\hline Diabetes & -0.113 & 0.585 & 0.037 & 1 & 0.847 & 0.893 & 0.284 & 2.812 \\
\hline Heart disease & 0.554 & 0.594 & 0.867 & 1 & 0.352 & 1.740 & 0.543 & 5.578 \\
\hline Hypertension & 1.215 & 0.562 & 4.677 & 1 & 0.031 & 3.369 & 1.121 & 10.131 \\
\hline $\begin{array}{l}\text { Respiratory } \\
\text { disease }\end{array}$ & -0.472 & 0.955 & 0.245 & 1 & 0.621 & 0.623 & 0.096 & 4.050 \\
\hline Cancer & 1.261 & 0.743 & 2.882 & 1 & 0.090 & 3.529 & 0.823 & 15.136 \\
\hline BMl & 0.072 & 0.765 & 0.009 & 1 & 0.925 & 1.074 & 0.240 & 4.817 \\
\hline Sex & 0.382 & 0.625 & 0.373 & 1 & 0.541 & 1.465 & 0.430 & 4.988 \\
\hline $\begin{array}{l}\text { Mechanical } \\
\text { ventilation }\end{array}$ & 0.418 & 0.546 & 0.585 & 1 & 0.445 & 1.518 & 0.521 & 4.428 \\
\hline
\end{tabular}

B: exponential; Cl: confidence interval; DF: Dickley-Fuller test; SE: standard error; sig: significance test; Wald: Wald test.

Again, confounding factors that need adjustment must be observed before jumping to the conclusion of significance as deemed by statistical tests.

Additionally, cardiovascular disease is a predictor for COVID-19 severity, ITU admission, and mortality. This again is linked to ACE2 receptors and progression to myocarditis, heart failure, and death. ${ }^{32}$

Patients with COPD are also at significant risk of poor COVID-19 disease progression and mortality. Many other studies have shown similar outcomes in patients with COPD and COVID-19,24,33,34 where significant number of patients were admitted to the ITU or had to undergo CPAP ventilation. ${ }^{35,36}$

Patients with cancer are especially vulnerable to infection and severe outcomes because of poor general health, immunosuppression, and the type of cancer and anticancer treatment regimen they are following. 37,38 Cancer was significantly associated with mortality in the patients in this study $(p=0.003)$.

In this study, diabetes was a predicter of mortality in linear regression; however, it did not reach statistical significance in multivariate analysis $(p=0.491)$. Several reports on patients with diabetes have shown a strong association between vulnerability, severe disease progression, and mortality when presenting with COVID-19.23,39-41 This is likely because of immunosuppression, defective metabolic systems, and associated morbidities of chronic complications of diabetes such as cardiovascular, renal, and cerebrovascular disease.

As this study is relatively small, caution should be taken when considering the generalisability of the results. It is, however, one of several studies to provide evidence on obesity as a risk factor for COVID-19 mortality.

\section{Limitations}

Firstly, this is a cohort of consecutive patients who were admitted to the $R U$ for respiratory support and possible escalation to the ITU. It is a relatively small study; however, the sample representation was adequately powered for statistical analysis. Secondly, a significant number of patients are still in hospital and are therefore not available for mortality analysis. 


\section{References}

1. Watanabe $M$ et al. Obesity and SARSCoV-2: a population to safeguard. Diabetes Metab Res Rev. 2020:e3325.

2. Simonnet $A$ et al. High prevalence of obesity in severe acute respiratory syndrome coronavirus-2 (SARSCoV-2) requiring invasive mechanical ventilation. Obesity (Silver Spring). 2020;28(7):1195-9.

3. Baker MG et al. Pandemic influenza $\mathrm{A}(\mathrm{H} 1 \mathrm{~N} 1) \mathrm{v}$ in New Zealand: the experience from April to August 2009. Euro Surveill. 2009;14(34):19319.

4. Morgan OW et al. Morbid obesity as a risk factor for hospitalization and death due to 2009 pandemic influenza $\mathrm{A}(\mathrm{H} 1 \mathrm{~N} 1)$ disease. PLoS One. 2010;5(3):e9694.

5. Chan JF et al. Middle East respiratory syndrome coronavirus: another zoonotic betacoronavirus causing SARS-like disease. Clin Microbiol Rev 2015;28(2):465-522.

6. Fischer-Posovszky P, Moller P. [The immune system of adipose tissue: obesity-associated inflammation]. Pathologe. 2020;41(3):224-9. (In German)

7. Agrawal $M$ et al. The immune system in obesity: developing paradigms amidst inconvenient truths. Curr Diab Rep. 2017;17(10):87.

8. Hegde V, Dhurandhar NV. Microbes and obesity--interrelationship between infection, adipose tissue and the immune system. Clin Microbiol Infect. 2013;19(4):314-20

9. Munoz $M$ et al. [Obesity and the immune system]. Nutr Hosp. 2004;19(6):319-24. (In Spanish)

10. de Heredia FP et al. Obesity, inflammation and the immune system. Proc Nutr Soc. 2012;71(2):332-8.

11. Intensive Care Units National Audit and Research Centre (ICNARC). 2020. Available at: www.icnarc.org. Last accessed: 21 August 2020.

12. Caussy $\mathrm{C}$ et al. Obesity is associated with severe forms of COVID-19. Obesity (Silver Spring). 2020:28(7):1175.

13. Barrasa $\mathrm{H}$ et al. SARS-CoV-2 in Spanish intensive care: early experience with 15-day survival in Vitoria. Anaesth Crit Care Pain Med. 2020;DOI:10.1016/j. accpm.2020.04.001.

14. Muscogiuri G et al. Obesity: the "Achilles heel" for COVID-19?
Metabolism. 2020;108:154251.

15. Kassir R. Risk of COVID-19 for patients with obesity. Obes Rev. 2020;21(6):e13034.

16. Sattar $\mathrm{N}$ et al. Obesity a risk factor for severe COVID-19 infection: multiple potential mechanisms. Circulation. 2020:142:4-6.

17. Centres for Disease Control or Prevention (CDC). 2020. Available at: www.cdc.gov. Last accessed: 21 August 2020

18. Hussain A et al. Obesity and mortality of COVID-19. Meta-analysis. Obes Res Clin Pract. 2020;DOI:10.1016/j. orcp.2020.07.002

19. Briand-Mesange $\mathrm{F}$ et al. Possible role of adipose tissue and endocannabinoid system in COVID-19 pathogenesis: can rimonabant return? Obesity (Silver Spring) 2020:DOI:10.1002/oby.22916.

20. Kassir R. Risk of COVID-19 for patients with obesity. Obes Rev. 2020:21(6):e13034.

21. Malavazos AE et al. Targeting the adipose tissue in COVID-19. Obesity (Silver Spring). 2020;28(7):1178-9.

22. British Obesity and Metabolic Surgery Society (BOMSS). 2020. Available at: www.bomss.org.uk. Last accessed: 21 August 2020

23. Sinclair AJ, Abdelhafiz AH. Age, frailty and diabetes - triple jeopardy for vulnerability to COVID-19 infection. EClinicalMedicine. 2020:22:100343.

24. Zhu J et al. Clinical characteristics of 3,062 COVID-19 patients: a meta-analysis. J Med Virol. 2020;DOI:10.1002/jmv.25884.

25. Leung $C$. Risk factors for predicting mortality in elderly patients with COVID-19: a review of clinical data in China. Mech Ageing Dev. 2020;188:111255.

26. Gheblawi et al. Angiotensinconverting enzyme 2: SARS-CoV-2 receptor and regulator of the reninangiotensin system. Celebrating the 20th anniversary of the discovery of ACE2. Circ Res. 2020;126(10):1456-74.

27. Schiffrin EL et al. Hypertension and COVID-19. Am J Hypertens. 2020;33(5):373-4

28. Wu C et al. Risk factors associated with acute respiratory distress syndrome and death in patients with coronavirus disease 2019 pneumonia in Wuhan, China. JAMA Intern Med. 2020:180(7):934-43.

29. Li $\mathrm{G}$ et al. No adequate evidence indicating hypertension as an independent risk factor for COVID-19 severity. Clin Res Cardiol. 2O20;DOI:10.1007/s00392-02001653-6.

30. Guan WJ et al. Clinical characteristics of coronavirus disease 2019 in China. N Engl J Med. 2020;382(18):1708-20.

31. Saetta M et al. Goblet cell hyperplasia and epithelial inflammation in peripheral airways of smokers with both symptoms of chronic bronchitis and chronic airflow limitation. Am J Respir Crit Care Med. 2000;161(3):1016-21.

32. Dong $\mathrm{N}$ et al. End-stage heart failure with COVID-19: strong evidence of myocardial injury by 2019-nCoV. JACC Heart Fail. 2020;8(6):515-7.

33. Chen P, Zhou B. Clinical characteristics of COVID-19 patients with abnormal liver tests. J Hepatol. 2020;DOI:10.1016/j.jhep.2020.04.028.

34. Li R et al. Clinical characteristics of 225 patients with COVID-19 in a tertiary Hospital near Wuhan, China. J Clin Virol. 2020;127:104363.

35. Tal-Singer R, Crapo JD. COPD at the time of COVID-19: a COPD foundation perspective. Chronic Obstr Pulm Dis. 2020;7(2):73-5.

36. Zhao $Q$ et al. The impact of COPD and smoking history on the severity of COVID-19: a systemic review and meta-analysis. J Med Virol. 2020;DOI:10.1002/jmv.25889.

37. Dai $\mathrm{M}$ et al. Patients with cancer appear more vulnerable to SARSCOV-2: a multi-centre study during the COVID-19 outbreak. Cancer Discov. 2020;10(6):783-91.

38. Chen $W$ et al. Cancer statistics in China, 2015. CA Cancer J Clin. 2016;66(2):115-32.

39. Gentile S et al. COVID-19 infection in talian people with diabetes: lessons learned for our future (an experience to be used). Diabetes Res Clin Pract. 2020:162:108137.

40. Guo W et al. Diabetes is a risk factor for the progression and prognosis of COVID-19. Diabetes Metab Res Rev. 2020;e3319:DOI:10.1002/dmrr.3319.

41. Klonoff DC, Umpierrez GE. COVID-19 in patients with diabetes: risk factors that increase morbidity. Metabolism 2020;108:154224. 